\title{
Linhas de vida, linhas do romance: uma percepção rizomática de "Amar-te a ti nem sei se com carícias", de Wilson Bueno
}

\author{
Marco Aurélio de Souza ${ }^{1}$ \\ Silvana Oliveira ${ }^{2}$
}

\section{Resumo}

Neste artigo, recorremos à percepção rizomática do fenômeno literário, tal como Gilles Deleuze e Felix Guattari apresentam nos primeiro e terceiro volumes de Mil Platôs (2011), para identificar no romance histórico Amar-te a ti nem sei se com carícias (2004), de Wilson Bueno, suas linhas de segmentaridade dura, maleável e de fuga. Daíresulta o reconhecimento de uma linha de fuga no romance histórico capaz de problematizar os limites de uma sociedade historicamente determinada e assim revelar as rachaduras perceptíveis na construção de sentidosidentitários e subjetivos na narrativa do passado.

Palavras-chave: romance histórico; desterritorialização; experiência do fora; Gilles Deleuze; Felix Guattari

\section{Life lines, novel lines: a rizomatic perception of "Amar-te a ti nem sei se com carícias", written by Wilson Bueno}

\footnotetext{
${ }^{1}$ Marco Aurélio de Souza é doutorando em Estudos Literários na Universidade Federal do Paraná. E-mail: aurelio.as25@yahoo.com.br.

${ }^{2}$ Silvana Oliveira é professora associada do departamento de Letras Vernáculas da UEPG.
} 


\section{Abstract}

In this article we adopt a rizomatic perception of the literary phenomenon based on the model presented by Gilles Deleuze and Felix Guattari in the first and in the third volume of Mil Platôs (2011) in order to identify the hard, flexible and escapist segmental structures in the historical novel Amar-teatinem sei se comcarícias (2004) written by Wilson Bueno. From this approach derives the recognition of an escapist line in the historical novel which can not only question the limits of a historically determined society, but also reveal the noticeable fissures on the construction of the identity and subjective senses in the narrative about the past.

Keywords: historical novel; deterritorialization; outside experience; Gilles Deleuze; Felix Guattari

Seja com a prosa limpa e precisa do jornalismo e dos contos, seja com a linguagem inventiva e experimental de Meu tio Roseno, a cavalo, ou ainda com o portunhol atravessado pelo guarani de Mar Paraguayo, Wilson Buenopode ser reconhecido como um exímio articulador/desarticulador de sua própria escrita. Em Amar-te a ti nem sei se com carícias ${ }^{3}$ (BUENO, 2004), o paranaense de Jaguapitã recriou a escrita oitocentista, com o bacharelismo, os cacoetes e a pompa parnasiana típica de fins do século XIX. Tratase de um romance histórico, portanto, e a erudição do autor não deixou faltar a ele as marcas e características apontadas pela historiografia como distintivas do período em questão.

À luz de algumas noções conceituais de Gilles Deleuze e Felix Guattari, apresentadas, sobretudo, em Mil Platôs, proponhouma leitura rizomática do romance de Wilson Bueno, buscando verificar de que forma o autor organiza o passado histórico sob a forma de um texto literário e, mais,identificando elementos essencialmente ligados à linguagem artística

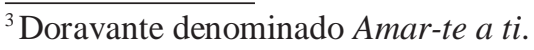


no romance, pontuo as linhas de fuga produzidaspela ficção de Bueno, movimentosqueligamo passado público de nossa cultura ao Foraabsoluto, por meio de um processo de desterritorialização e catarse literária.

\section{Segmentação dura e imagem do passado}

Somostodos feitos de linhas, dizemDeleuzee Guatarri. Arealidade éfeitadelinhas. Linhas pelas quais traçamoscoordenadas, construímos um mapa.Em um romance, encontramos linhas de escrita, que "se conjugam com outras linhas, linhas de vida, linhas de sorte ou infortúnio, linhas que criam a variação da própria linha de escrita, linhas que estão entre as linhas escritas" (DELEUZE, GUATTARI; 1995, p. 72). Um rizoma é feito de linhas. Enquanto escrevo, traço também uma linha, que se liga com outras linhas, linha que cruza, conecta ou faz fugir.

Existem linhas de diferentes tipos: elas não param de se misturar umas com as outras. Quando dizemos que uma linha é de tal espécie, logo percebemos nela outra linha, que diverge da primeira. Há pelo menos três tipos de linhas que são bem marcadas:

[...] de segmentaridade dura e bem talhada, de segmentação molecular e em seguida a linha abstrata, a linha de fuga, não menos mortal, não menos viva. Na primeira há muitas falas e conversações, questões ou respostas, intermináveis explicações, esclarecimentos; a segunda é feita de silêncios, de alusões, de subentendidos rápidos, que se oferecem à interpretação. Mas se a terceira fulgura, se a linha de fuga é como um trem em marcha, é porque nela se salta linearmente, pode-se enfim falar aí "literalmente", de qualquer coisa, talo de erva, catástrofe ou sensação, em uma aceitação tranquila do que acontece em que nada mais pode valer por outra coisa. (DELEUZE, GUATTARI, 1995, p. 77) 
Os binarismos que compõem a estrutura social, as formas rígidas de entender a realidade, constituem linhas molares, de segmentação dura. As arborescências, as estratificações de um sentido, constituem linhas de segmentaridade dura. Elas nos dão segurança. Estabilizam nossa visão da realidade. Comelas, dizemos: a realidade é assim; a natureza, a sociedade, o passado são assim. A característica básica do romance histórico, na perspectiva adotada aqui, é ter sua linha de segmentaridade dura formada por aquilo que Ankersmit denominou de "imagens do passado" (ANKERSMIT, 2001, p. 156).

Para o filósofo da história, tais imagens são o resultado do processo de seleção que os historiadores (ou aqueles que trabalham com vestígios do passado) operam na elaboração discursiva de sua visão sobre o passado, definindo que partes de determinado recorte temporal possuem relevância, e quais os enunciados que individualizarão esta parte do passado sob a forma de um texto.Por se tratar de uma narrativa que privilegia a própria linguagem, além do lado confessionale sentimentalde seu narrador, Amar-te a ti explora com destreza uma imagem do passado relacionada ao medo no século XIX, que nos remete ao clássico estudo de Celia AzevedoOnda negra, medo branco(1987).Por meios ficcionais, a "série de brancos ou 'esfolados' bem-nascidos e bem-pensantes que, durante todoo século XIX, temeram acabar sendo tragados pelos negros mal-nascidos e mal-pensantes" (AZEVEDO, 1987, p. 19) pode ser vislumbrada na figura do próprio Leocádio, o narrador e protagonista, anti-abolicionista que, aqui e ali, imprime em suas notas as tonalidades do medo que sente dos antigos escravos, já libertos ao tempo de sua escrita.

Amante das letras jurídicas e da poesia, Leocádio também pode ser lido enquanto uma personificação do ambiente literário do período, o mesmo ambiente que, anos mais tarde, os modernistas da semana de 22 buscaram perturbar. Em sua escrita, salta aos olhos do leitor o pedantismo e o vocabulário bacharelesco típicos de uma geração que, sem a mesma habilidade, tinha em Bilac seu mestre e seu caminho. O preciosismo com 
as palavras manifesto, sobretudo, na larga utilização de termos pouco usuais e no lirismo exagerado de construções literárias que soam um tanto gratuitas, formam, junto das referências a grandes escritores da época, um perfil literário não apenas de Leocádio, mas de um senso comum intelectualizado do final do século XIX brasileiro.

Aliado ao culto pelas "Belas Letras", as posições conservadoras do narrador e sua visão de mundo altamente elitista constituem, se não uma contradição, uma tensão ressoando no seio de sua escrita. Neste sentido, a desconfiançade Leocádio em relação ao seu barbeiro, o Eurípede, expressa precisamente tal combinação, aos olhos de hoje, indigesta: em passagem relacionada ao tema (BUENO, 2004, p. 30), logo após uma manifestação racista com a defesa irrestrita da má índole do homem de cor, expressão do imaginário das elites brancas do período, o narrador engatilha mais uma de suas digressões existenciais, comdireito ao pedantismo habitualde suas especulações vazias sobre a "verdade do ser". O que se inicia como alerta preconceituoso, termina numa máscara de grandiosidade filosófica que, vista de perto, é quase nada.

Daíque, no exame das imagens do passado presentes no romance, uma imagem maior parece contaminar todas as demais. O mascaramento das tensões e dos conflitos sociais do período por meio da linguagem parece ser a expressão do conjunto estético em seu todo, a imagem do passado atrelada à obra de Bueno. Ao longo do romance, nos momentos em que a escrita de Leocádio, comos exageros parnasianos e maneirismos de época, parece se questionar sobre a sua própria identidade, ela realiza o contrário, camuflando o seu autor e, com isso, escondendo também outra identidade "verdadeira" do século XIX. No fim, as fissuras da História e do Sujeito continuam lá, por debaixo dos termos difíceis e da sintaxe empolada, nos lugares mesmos em que o narrador, ou o registro do passado, mais tentou, em vão, escondê-las. Na imagem do passado deAmar-te a ti, um Brasil que, tal como uma velha dama a esconder suas rugas, camufla seus conflitos, seus problemas sociais e sua mentalidade 
conservadora com o batom e o pó-de-arroz da língua pretensamente culta - a bacharelesca língua portuguesa das elites.

\section{Os vazios e o impulso desterritorializante}

Se a linha de segmentação dura é a dos sentidos fixos, bem localizáveis e estabilizados, outra é a linha de segmentação maleável, ou linha molecular. Estas linhas de um segundo tipo, mais do que erigir um monumento, o fazem tremelicar, fazem-nos ver no monumento erguido pelas linhas duras algo de diferente, quem sabe mesmo algo de novo. São como quantas de desterritorialização, arremessando pacotes de intensidade e potências estranhas ao sentido estratificado pela rigidez das linhas molares.

EmAmar-te a ti, atravessada na ambientação históricaresponsável pela subjetivação de Leocádio, nas imagens do passado que organizam e conferem densidade ao personagem narrador, há uma trama repleta de silêncios e vazios. São eles quem nos impelem para a linha maleável do romance.A relação enigmática de amor/ódio do narrador pelo amigo Licurgo Pontes, bem como a aura de mistério que cerca a morte de sua esposa Lavínia, são os impulsos fundamentais das reflexões e memórias do narrador. Mas nada se esclarece. Se existe umenigma a ser solucionado, ele flutua pelas inúmeras lacunas da narrativa - lacunas que sugerem ora uma, ora outra direção, fazendo com que o leitor, na busca por levantar a arborescência do romance, veja seu intento fracassar diante da porosidade da linguagem de Leocádio.

Na terminologia de Iser (2002), podemos entender a construção romanesca de Amar-te a ti através das noções de vazios e negações. Para o teórico, estes espaços de indeterminação são aquilo que impulsiona e dá vida a uma dinâmica de leitura fundada na expectativa decorrente do não-dito e na quebra ou correspondência desta expectativa de acordo com aquilo que está presente no texto.Assim, tais vazios são os lugares 
oferecidos pelo texto à ocupação pelo leitor, constituindo um ponto fundamental de interação entre ambos. É através dos vazios que uma narrativa pode programar a interação assimétrica entre texto e leitor. Do mesmo modo, a ficção histórica de Wilson Bueno parece dar abertura a seu leitor para que, não delimitando uma solução única para a trama do romance, elabore as saídas possíveis deste labirinto de memória. Mas se a fragmentação e a indeterminação estimulam o preenchimento da trama pelo leitor, em Amar-te a ti, tais recursos igualmente fragilizam toda e qualquer resposta definitiva que se queira dar para as questões levantadas.

Assim, sabemos que Lavínia faleceu no desembarque de uma viagem realizada a Juiz de Fora. Leocádio, ausente no momento, volta ao fato imbuído de desconfianças. Licurgo estava lá quando da morte. Ele quem deu ao viúvo as trágicas notícias. Antes de procurar as circunstâncias do ocorrido, o burocrata especula primeiro sobre as próprias razões da viagem:

Ver fantasmas ali onde só existiam lacunas, a ausência de Lavínia afundando-me num vácuo irremediável, sabiamconstituir-me os dias. Quase uma semana jáse ia com ela a Juiz de Fora e era como se a casa não me coubesse ao corpo, e nem eu a ela inteiramente. Por que Lavínia embarcara sem mim? Que gesto aquele, quase petulante, que a fizera sair a sítio tão distante, a hospedar-se a uma prima de segundo grau? (BUENO, 2004, p. 60)

Resposta de Lavínia: saudades da prima. Nem mesmo ao leitor Leocádio confia explicitamente qual a sua hipótese. Sabe-se apenas que a dúvida não o abandona, e que a resposta the pareceu insuficiente. Retornando ao tema em momento adiante, pouco falta a Leocádio para que acuse o amigo Licurgo: "Quando chegamos ao Cais Pharoux, desde longe percebi Licurgo, preocupado, neurastênico, de maus modos e jeitos. E aquele era o meio como parecia eximir-se de toda culpa" (BUENO, 
2004, p. 92). Mas se há alguma culpa, qual é ela? O não-dito, somado a considerações vagas, sugestões mais ou menos veladas, fazem com que o leitor tome "como pensado o que não foi dito" (ISER, 2002, p. 90).

Deste modo, ao longo de toda a narrativa de Amar-te a ti, o leitor desliza por um pantanoso terreno de incerteza e imaginação. Em capítulo intitulado "A caça e o caçador", Leocádio narra um episódio em que, já viúvo, aposentado e morando com a irmã Elvira, recebe uma visita de Licurgo.Marcado pela tensão dos diálogos entre o narrador e seu jovem amigo, o capítulo é repleto de insinuações acerca da atraçãoque Leocádio sentia por Licurgo, sempre permeadas pelos vazios narrativos, que fazem o leitor acreditar em um pano de fundo não pronunciado. Deste modo, a dubiedade do romance perpassa também pela dubiedade dos diálogos descritos por Leocádio, daquilo que os personagens dizem uns aos outros, sempre revelando e escondendo simultaneamente. $\mathrm{O}$ leitor terá que conviver com a dúvida, mesmo quando as pistas indicam um caminho a seguir.

Amar-te a ti, portanto, é narrativa dotada de verdadeiros platôs em que os sentidos se dão por movimento de redemoinho, os quais exigem a cooperação do leitor, a risco de, em caso contrário, a força do romance se esvair. Os desejos de Leocádio, sua latente ou possível homo ou bissexualidade, os fantasmas relacionados à morte de Lavínia (homicídio, suicídio ou acidente?), todos estes quantas de desterritorialização fazem comque o leitor suspeite de todo sentido que parecia seguro e estratificado. Bem marcado pelo contexto histórico que o envolve, o narrador do romance, que antes parecia ter um rosto, desfigura-se com as flutuações da linha molecular-é esse ainda aquele homem que pensávamos que fosse? Mas afinal, quemé Leocádio? Pergunta que, pela relação de contiguidade anteriormente já estabelecida, nos conduz a outra questão, de maior abrangência: é esse ainda o século XIX de que falávamos?

A estratificação do passado no narrador, chacoalhada pelos enigmas da trama, parece prestes a ruir. Há um processo de 
desterritorialização em curso. Entretanto, falta ainda o elemento que trace a linha de fuga de todo o sistema. É preciso encontrar o momento em que Leocádio, e com ele a História significada, perde o seu rosto, o seu sentido, desfaz, enfim, a sua arborescência.

\section{A experiência do Fora, ou sobre como Leocádio desfaz sua arborescência}

Até aqui, apontei para as linhas de segmentaridade dura e maleável presentes na narrativa de Amar-te a ti, mas há ainda uma terceira linha, de fuga ou abstrata, eé ela quem realiza o movimento de desterritorialização, que nos leva ao Fora absoluto. Esta linha não se coloca contra ou ao lado das interpretações canônicas de determinados momentos históricos, mas faz do romance histórico um experimento acerca dos limites de uma sociedade historicamente determinada. Pois as linhas de fuga

não consistem nunca em fugir do mundo, mas antes de fazê-lo fugir, como se estoura um cano, e não há sistema social que não fuja/escape por todas as extremidades, mesmose seus segmentos nãoparamde seendurecer para vedar as linhas defuga. (DELEUZE. GUATTARI; 2011, p. 78)

É pela linha de fuga que, no romance de Bueno, experimentamos o passado, e não apenas o observamos, sob a forma de uma representação.

Há um componente de realidade que, nos domínios de uma literatura meramente referencial, não conseguiríamos apreender.É Ereciso que este Real se apresente sob nossos olhos, sem interpretação, semestratificação, sem um sentido construído e atribuído. Mas qual seria o cano que se estoura, a desterritorialização absoluta dentro desteterritório demarcado?

Nada mais que imitar: a linha de fuga se produz num devir, e não importam os pontos de saída ou chegada, mas sim o trajeto que se faz entre um e outro. Nada mais que se referir, nada mais que tomar como 
objeto.A linha de fuga é a força liberada, é o cano que se estoura, é a linha que se coloca em relação com o Fora ${ }^{4}$. Esta experiência do Fora se dá em dois níveis: diegético e extra-diegético. Não somente Leocádio encontrao seu Fora como também, por meio dele, o leitor experiencia o Fora que é a própria narrativa de Leocádio.

Entende-se, aqui, que a experiência do Fora no texto literário se dá por meio das linhas de fuga traçadas pela ficção. Mas se aceitamos, entretanto, que a linha abstrata ou de fuga se produz num devir, é necessário ainda definir, na esteira de Deleuze e Guattari, o que se entende por devir. Em Mil Platôs, temos que o devir é o próprio "movimento pelo qual a linha libera-se do ponto, e torna os pontos indiscerníveis: rizoma, o oposto da arborescência, livrar-se da arborescência. O devir é uma antimemória" (DELEUZE, GUATTARI; 1995, p. 96).A expressão "antimemória" não é gratuita. A memória, em sua íntima relação com o passado, é aquilo que nos estratifica, que nos preenche com uma subjetividade, é o material pelo qual encontramos um rosto para assumir. No devir ou na linha de fuga, o corpo se esvazia de memória - ao mesmo tempo, não é mais o que era antes e ainda não é o que um dia poderá ser. A definição, neste ponto, assemelha-se à noção de "momento do evento revelador" (ANKERSMIT, 2012, p. 260), utilizada pelo filósofo da história Ankersmit. Para o teórico holandês, tal momento consiste exatamente no intervalo entre passado e presente, entre sujeito e objeto, em que não existem códigos de leitura disponíveis para qualquer tentativa de compreensão. O que há, sobretudo, é uma experiência. Ela nos leva a um estágio posterior de conhecimento, no qual retornam as fronteiras entre passado e presente, e onde enfim podemos outra vez analisar aquilo que passou - agora com um olhar renovado. Ou seja, tal momento é o ${ }^{4}$ Ao contrário do que pode parecer ao senso comum, o conceito do Fora não deve ser
visto como algo que nos afasta da realidade, mas sim como um elo de ligação. Maurice
Blanchot utilizava-se do conceito exatamente para pensar a relação da literatura com o
Real. Para o filósofo, a literatura pode constituir "uma experiência que, ilusória ou não,
aparece como meio de descoberta e de um esforço, não para expressar o que sabemos,
mas para sentir o que não sabemos" (BLANCHOT, 1997, p. 81). 
que institui uma separação, uma ruptura, um antes e um depois. Durante o momento, no entanto, tudo é desorganização, caos, experiência pura da realidade, contato com o Fora.

Em minha leitura do romance de Wilson Bueno, tal momento revelador, epifania de Leocádio e de seu leitor, não será encontrado nos segredos de seu narrador. As inúmeras especulações sobre a morte de Lavínia e o papel de Licurgo na trama servem como despiste para aquilo que é a experiência do Fora na narrativa. Engana-se, portanto, quem procura em Amar-te a ti pela resposta dos mistérios envolvidos na relação de Leocádio, Licurgo e Lavínia, acreditando ser aí que o enredo do romance adquira consistência.

Dir-se-ia que é na linguagem que reside o interesse da obra, mas isto é pouco, e não nos diz muita coisa sobre o título específico. Percebe-se, deste modo - e para retornar à noção de antimemória -, mais facilmente a linha de fuga do narrador de Amar-te a ti se observamos atentamente sua relação com o tempo. Nas imagens do passado utilizadas pelo romance, adquire vulto e importância aquelas relativas à mentalidade das elites frente ao processo de abolição da escravatura e a marginalização da população negra: aí é que, com maior intensidade, pode-se perceber a força da experiência do narrador. As imagens do passado relacionadas ao tema são os tijolos retirados do muro de Leocádio, que fazem toda a edificação ruir, tornar-se um corpo desorganizado de destroços.

Necessário, contudo, frisar que os mistérios não-revelados da memória de Leocádio possuem também sua função. É com eles que a desorientação do narrador se inicia. Ainda que não saibamos o que aconteceu, sabemos que a lembrança e a tentativa frustrada de dominar a lembrança empurram Leocádio para outro ponto. Assim, "tudo é o sentimento confuso e indiscernível de algo ou alguma cousa a quebrarse dentro, feito eu fosse um boneco de armar "(BUENO, 2004, p. 188), e os quanta de desterritorialização traçam linhas moleculares em Leocádio. 
E como se algo maior estivesse nascendo dentro do menor, "fica sendo como se o corpo não pudesse conter o próprio corpo "(BUENO, 2004, p. 188).É a intensidade das porções de desterritorialização que aumenta.

Falecida a Lavínia, distante o Licurgo, Leocádio se entrega à solidão desiludida de suas memórias no quarto do Majestic. É ao fim do romance que o burocrata narra uma última aventura que é o seu devir, é a linha de fuga que, em meio ao seu cotidiano de depressão e decadência, despontou na superfície de sua vida. E a fuga, de fato, é ao mesmo tempo sutil e arrebatadora.Levado pelo amigo Villaça para uma roda de voltarete na birosca, Leocádio observa um mulato sentado ao fundo, olhar fixo no seu - dois olhos em brasa. Leocádio, indo ao banheiro, esquiva-se "cuidando fugir do que, através dos olhos (...) devassava a alma incerta" (BUENO, 2004, p. 189). No fétido mictório, a mão grande do mulato o agarra por trás: cochicho de acento angola que pede patacas. Leocádio oferece o que tem, mas o negro quer mais.

Instei-o a que bebesse comigo e não conto tudo o que foi a tarde derruída, escusos de Saúde e Lapa, nova noite de álcool a emendar em ainda outra manhã, o negro a acompanhar-me as exagerações, até que, exausto de mim e das horas trôpegas, caímos, um sobre o outro, na cama imunda de uma hospedaria do centro da cidade. (BUENO, 2004, p. 189)

Leocádio, velho conservador, partidário do Império, antiabolicionista ferrenho, crente da ausência de alma e espírito nas pessoas "de cor", caído na cama junto de um mulato - dois diase mais em exageros como "capoeira”. Será o mesmo indivíduo este último e aquele primeiro? Onde o antigo Leocádio, aquele que desconfiava do próprio barbeiro que cuidava de seus cabelos, aquele homem que enxergava o mundo em um inexorável preto e branco?Se são ainda a mesma pessoa, não possuem, entretanto, o mesmo rosto. 
As relações de Leocádio com o mulato são o cano que se estoura na vida do velho narrador. Ele agora desfaz pouco a pouco a árvore significante que habita em si mesmo. Se havia um rosto que pudesse nos fazer identificá-lo, ao qual olhávamos e dizíamos, esse é Leocádio, assim é o século XIX, tal rostidade se apaga com borracha quando o velho se deixa levar pelos desejos inconfessáveis que, atravessando o muro de sua subjetividade, o colocam em contato íntimo com o seu Fora, o sexo esvaziando todas as coordenadas de uma subjetividade, todos os sentidos que pudessem impedir uma epifania do narrador. Aí a desterritorialização absoluta de Leocádio que, aos setenta e quatro anos, após exagerações e desmedidas, decide findar suas elocubrações baldias e dedicar-se ao gamãoe ao voltarete. Leocádio se reterritorializa, mas algo de profundo diverge, e nada será como antes.

A cena não contesta nem reafirma nenhuma de nossas verdades sobre o passado. Indo além, o caso nos faz questionar os próprios limites de nossa arborescência, de nossa rostidade, sugerindo que, assim como Leocádio traça sua linha de fuga e se permite desorganizar aquilo que dava como certo, também a História tem as suas fugas em pecados inconfessos. Será o próprio romance histórico uma linha de fuga da escrita da história? Em todo caso, ela quem pode nos fazer experimentar o Fora dos organismos históricos, a fuga das imagens já construídas e estabilizadas.

Mas mergulhar no caos é tarefa que exige prudência. Se, para permitir um outro dentro de si mesmo, Leocádio se desterritorializa, sua reterritorialização nos mostra que o narrador foi cuidadoso o suficiente para guardar em si mesmo porções de subjetividade, pedaços de seu antigo rosto que, depois da fuga, voltou a assumir. Pois na experiência do Fora, na desterritorialização absoluta, corre-se sempre este risco: perder a ligação com a realidade dominante, com esta teia de significações que o devir não se cansa de nublar. Leocádio desfaz sua arborescência, desfaz o seu rosto, mas conserva o suficiente para retornar à realidade dominante - não comete o suicídio, não se deixa esquizofrenizar. Tudo mudou, e é 
precisamente este o efeito da linha de fuga do indivíduo, mas a linha dura é o que nos dá segurança, e é para ela que queremos sempre retornar. Leocádio volta a se preencher com os significados de seu tempo, com as posições que estratificam o século XIX dentro de si.

Nenhuma palavra sobre o relâmpago de desejo, de excentricidade, de permissividade e antimemória. Leocádio volta ao ritmo dos dias, sem se preocupar com o que se passou, pois sabe que já não está numa linha de fuga, que pode voltar a compreender o mundo, a simplificá-lo e suavizá-lo com suas categorias. Seu rosto, entretanto, e a história que ele carrega, foram desfigurados, perderam sua identidade, jamais serão os mesmos outra vez.

\section{Considerações finais}

Coerenteà leitura deAmar-tea ti aquioperada, podemos apresentar o texto literário de cunho histórico enquanto um contraponto gramíneo ao modelo arborescente da historiografia. Os romances históricos, deste ponto de vista, trabalham com a articulação e desarticulação de imagens do passado, inseridos em um contexto mais amplo de uma cultura ou imaginação histórica. Este processo, contudo, dá-se sempre em um nível subordinado ao projeto estético e artístico, que visa propiciar uma forma de saber própria da literatura. $\mathrm{Na}$ defesa deste saber, fruto de uma função catártica, recorro à noção de uma desterritorialização operada pela linguagem artística proporcionando ao leitor literário uma experiência do Fora.A literatura, nesta perspectiva, faz fugir, estoura o cano, desarticula os sistemas - não se propõem a trocar X por Y, mas a forjar uma distância emrelação ao alfabeto inteiro.Trata-se da linguagem colocada em posição de experimento.

Cabe frisar, contudo, que a aventura de Leocádio não é apenas a desterritorialização do sujeito, mas também da História. Sua relação de 
contiguidade permanece aí também. Enquanto experienciamos o relato de uma vida, experienciamos os sentidos que ela acumula e constrói. Em um romance histórico, estes sentidos cruzam com os sentidos de um passado público elaborado pela historiografia e demais discursos sobre o passado. Pois as linhas duras, moleculares e de fuga não são apenas dos livros ou das pessoas, mas também das sociedades e suas histórias.

Como ressalta Tatiana Salem Levy, entender a literatura como uma experiência do Fora é entender que ela "não é uma explicação do mundo, mas a possibilidade de vivenciar o outro do mundo" (LEVY, 2011, p. 27). Assim, ao nos entregarmos à literatura ficcional, não estamos nos afastando do real, já que os "personagens, as situações, as sensações nos são apresentados de forma a nos fazer senti-los, a nos fazer vivêlos. Justamente por esse motivo, essa experiência é profundamente real" (LEVY, 2011, p. 20). Pode-se dizer, portanto, que na catarse do texto literário, experienciando sentimentos e emoções que nos dão acesso ao Fora deste mundo, relembramos e aprendemos continuamente a função do devir. Não chegamos a um significado, mas sim nos deixamos flutuar por entre todos os significados. Não somos homem ou mulher, criança ou adulto, natureza ou cultura, não somos nenhum dos pólos binários e, estranhamente, sentimo-nos como todos eles em algum momento.Devirmulher, devir-criança, devir-cão, devir-louco: afinal, que mais "se há de fazer com a vida, senão vivê-la até a última gota e o irrevogável suspiro?" (BUENO, 2004, p. 191).

\section{Referências}

ANKERSMIT, F. R. Resposta a Zagorin. In: Topoi. Rio de Janeiro, mar. 2001, pp. 153-173.

. A escrita da história: a natureza da representação 
histórica. Trad. Jonathan Menzes... [et al.]. Londrina: Eduel, 2012.

AZEVEDO, Celia Maria Marinho de. Onda negra, medo branco; o negro no imaginário das elites - século XIX. Rio de Janeiro: Paz e Terra, 1987.

BLANCHOT, Maurice. A parte do fogo. Rio de Janeiro: Rocco, 1997.

BUENO, Wilson. Amar-te a ti nem sei se com carícias. São Paulo: Editora Planeta do Brasil, 2004.

DELEUZE, Gilles; GUATTARI, Felix. Mil Platôs-capitalismo e esquizofrenia. Vol. 2. Trad. Ana Lúcia de Oliveira e Lúcia Cláudia Leão. Rio de Janeiro: Editora 34, 2011.

. Mil Platôs - capitalismo e esquizofrenia. Vol. 3 Trad.

Aurélio Guerra Neto. Rio de Janeiro: Editora 34, 2012.

.Mil Platôs-capitalismo e esquizofrenia. Vol. 4 Trad. Ana Lúcia de Oliveira e Lúcia Cláudia Leão. Rio de Janeiro: Editora 34, 1995.

ISER, Wolfgang. A interação do texto com o leitor. Em: LIMA, Luiz Costa. A literatura e o leitor: textos de estética da recepção. 2 ed. São Paulo: Paz e Terra, 2002.

LEVY, Tatiana Salem. A experiência do fora: Blanchot, Foucault e Deleuze. Rio de Janeiro: Civilização Brasileira, 2011. 